\title{
Influence of College Adjustment and Social Support on Career Development Level of College Students Who Majors in Health or Social Welfare
}

\author{
Jung-yeon Park ${ }^{1}$, Soon-mi Park ${ }^{2}$ \\ ${ }^{1}$ Department of Clinical Pathology, Jinju Health College, Jinju, Korea \\ ${ }^{2}$ Department of Welfare \& Administration, Jinju Health College, Jinju, Korea
}

\section{보건·복지계열대학생의 대학생활적응과 사회적 지지가 진로발달수준에 미치는 영향}

박정연 ${ }^{1}$, 박순미 ${ }^{2}$

${ }^{1}$ 진주보건대학교 임상병리과, ${ }^{2}$ 진주보건대학교 복지행정계열

\begin{abstract}
The purpose of this study was to investigate the influence of college adjustment and social support on career development for college students majoring in health or social welfare. For this purpose, a survey was conducted in the Gyeongsangnam-do area. There was a total of 203 study participants. Data were collected with a set of questionnaires and analyzed by a multiple regression analysis. The results of this study are summarized as follows. First, the mean of main variables are as follow; career development was 3.54, college adjustment was 3.07, social support was 3.59. Second, by using a multiple regression, college adjustment and social support had a positive effect on career development. In other words, higher the college adjustment and higher the social support, the higher the career development. Third, academic adjustment among the sub-areas of college adjustment and friend support among the sub-areas of social support had a significant effect on career development level. Based on these results, implications for research and practice were discussed.
\end{abstract}

Key words: College adjustment, Social support, Career development level

This is an Open Access article distributed under the terms of the Creative Commons Attribution Non-Commercial License (http://creativecommons.org/licenses/by-nc/4.0) which permits unrestricted non-commercial use, distribution, and reproduction in any medium, provided the original work is properly cited.

Copyright @ 2017 The Korean Society for Clinical Laboratory Science. All rights reserved.
Corresponding author: Jung-yeon Park

Department of Clinical Pathology, Jinju Health College, 51 Uibyeong-ro, Jinju 52655, Korea

Tel: 82-55-740-1845

Fax: 82-55-743-3010

E-mail: park1408jy@hanmail.net

Received: May 4, 2017

Revised $1^{\text {st: }}$ : May 23, 2017

Revised $2^{\text {nd: }}$ : June 1, 2017

Revised $3^{\text {rd: }}$ June 8, 2017

Accepted: June 9, 2017

\section{서 론}

대학시기는 또한 진로발달단계 상 구체적인 직업에 대하여 탐색하고 직업을 선택해야 하는 시기로, 대학생들에게 진로는 더 없이 중요한 문제이다[1]. 진로결정의 중요한 시기인 대학 시 기에 자신의 진로를 탐색하고 결정해야 하는 중요한 과제에 직 면하게 된다[2,3].
일반적으로 진로결정수준은 대학의 전공 및 직업선택의 확 신 정도, 자신의 개인적 특징이나 기회의 불확실성에 대한 평가 또는 미결정 정도에 대한 반작용 등 여러 측면에서 조명되는 개 념으로서 학생들의 학업 및 직업 선택과 관련한 진로결정의 진 행수준과 장래의 진로에 대한 확고한 결정의 정도를 의미한다 [4]. 이러한 진로결정수준에 영향을 미치는 요인에 관한 연구를 살펴보면 자기효능감, 자아정체감과 같은 개인의 내적 요인을 
중심으로 진로결정수준과 상관이 있다고 제시한 연구들[5-7] 이 대부분이다. 하지만 이렇게 중요한 시기에 진로발달 과업을 잘 수행하기 위해서는 무엇보다 개인을 둘러싸고 있는 다양한 사회적 체계로부터의 지지가 필요하다.

대학생활의 적응은 학생들에게 개인의 지적 욕구뿐만 아니 라사회적, 심리적 욕구를 충족할 수 있는 기회를 제공하여 바람 직한 태도를 지닌 사회 구성원으로 살아갈 수 있는 기반을 마련 해 주는 것이라 할 수 있다[8].

대학생활적응은 매우 다차원적인 현상으로서 다양한 요구들 이 뒤따르며 이러한 요구에 적절한 반응을 할 수 있는지 없는지 가 결과적으로 적응의 여부를 결정할 수 있다[9].

사회적 지지는 개인이 적극적으로 진로준비를 할 수 있도록 도와주는 긍정적인 자원을 의미한다[10]. 또한 사회적 지지는 어떤 개인이 자신이 가진 대인 관계에서 얻을 수 있는 포괄적인 도움과 원조 등 긍정적인 자원이다[11]. 사회인지 진로이론에 서는 사회적 지지를 개인이 적극적으로 진로행동을 할 수 있도 록 도와주는 모든 것으로 사회적 지지를 진로장벽과 함께 진로 목표의 설정 및 목표의 실행에 영향을 미치는 맥락적 변인의 하 나로서 진로선택을 추구하는 과정에서 경험할 것으로 예상되는 지지라고 설명하고 있다[10].

진로결정수준에 영향을 미치는 요인으로 사회적 지지, 대학 생활 적응 등의 요인을 살펴본 연구들도 있는데, 사회적 지지와 진로결정수준의 관계에 대해 사회적 지지를 높게 인식한 대학 생은 진로선택을 더 잘 준비하며[12], Whiston\&Keller [13]도 사회적 지지가 개인의 진로준비행동이 가능하도록 돕는다고 보 고하였다.

한편, 보건 · 복지계열대학생의 전공과목에 대한 교육과정은 엄격하고 과중한 학습과 임상실습을 겸해야 하며, 이런 과정을 성공적으로 적응해야 한다. 또한 지역사회 주민의 사회 심리적 요인을 보살피고 관리할 수 있는 역량 있는 전문인으로서 나아 기기 위한 교과과정을 이수함으로써 대학생활 적응과 자신들을 둘러싼 다양한 사회적 지지 체계 요인들을 긍정적으로 개발하 는 것이 필요하다. 나아가 이러한 대학생의 대학생활적응과 사 회적 지지가 진로발달에 영향을 미치는 것을 살펴봄으로써 향 후 전문 직업인 양성에 필요한 제반 요인을 연구하는 것은 매우 필요하다.

이에 대학생의 진로발달을 지원하는 요인에 대한 연구가 필 요하며, 본 연구는 대학생들의 진로발달 내지 진로결정수준에 관한 연구가 대체로 개인적 요인에 집중되는 한계를 극복하고 자, 사회인지 진로이론에 근거를 두고 대학생활적응과 사회적 지지가 보건 · 복지계열 대학생들의 진로결정수준에 미치는 영
향을 살펴보고자 한다.

\section{재료 및 방법}

\section{1. 연구모형}

본 연구는 선행연구 결과를 토대로 보건 · 복지계열대학생들 의 대학생활적응 정도와 사회적 지지 수준, 진로발달 수준 정도 를 살펴보고, 이들의 특성별 진로발달 수준 정도가 어떻게 다르 며, 이러한 진로발달 수준에 영향을 미치는 변인들이 어떻게 나 타나는가를 살펴보고자 하였다. 이에 대한 연구모형은 Figure 1 과 같다.

\section{2. 연구대상 및 자료수집 방법}

본 연구의 대상은 경상남도 $\mathrm{G}$ 지역과 J지역 대학에서 보건 · 복지계열을 전공하는 대학생을 대상으로 하였으며, 표본추출 방식은 임의표본추출방식을 활용하였다. 이들을 대상으로 2016년 12월 1일부터 16일까지 구조화된 설문지를 배포하고 설문조사의 의도와 목적을 설명한 다음 자기기입방식으로 조사 하였다. 조사에 참여한 학생은 223 명이었으나 내용의 불성실한 정도를 고려하려 자료 분석이 불가능한 대상자를 제외하고 총 203명을 연구대상으로 분석하였다.

\section{3. 변수의 조작적 정의}

본 연구의 종속변수는 진로발달수준으로, Shin 등[14]에서 활용한 진로발달수준 하위항목을 사용하였으며, '매우 그렇다 5점'에서 '전혀 그렇지 않다 1점' 으로 5점의 Likert 척도로 구성 되어 있는데 점수가 높을수록 진로발달수준이 높은 것을 의미 한다.

척도의 내적 일관성 측정 결과, Chronbach's $\alpha=0.832$ 로 나 타났다.

본 연구의 독립변수는 대학생활적응과 사회적 지지로, 대학

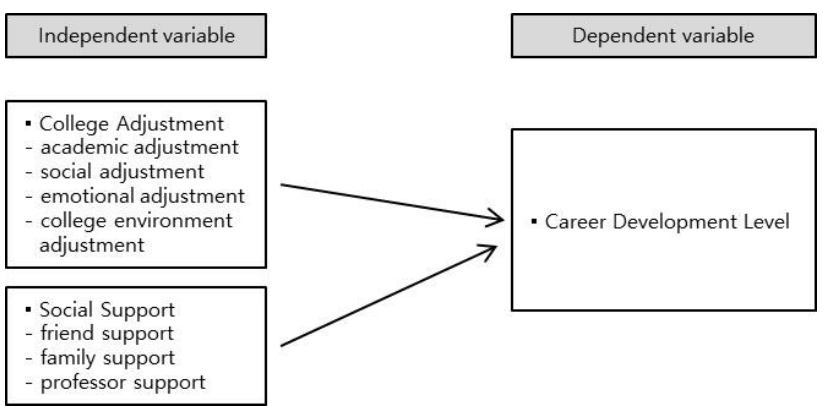

Figure 1. Research model. 
생활적응 척도(Student Adjustment to College Questionnaire; $\mathrm{SACQ)}$ 는 Baker와 Siryk [2]가 제작한 것을 Park과 Chong [15] 이 사용한 척도를 사용하였다. 이 척도는 대학생활적응 정도를 자기보고식으로 알아보는 검사로 총 67문항으로 구성되어 있 다. 전체 문항들은 대학의 교육적, 학업적 요구에 관한 학업적응 (24문항), 대인관계 및 사회적 요구와 관련된 사회적응( 16 문 항), 심리적 혹은 신체적 불편감을 나타내는 정서적응(16문항), 대학에 대한 유대정도와 대학의 질에 대한 대학만족도, 그리고 학업적 목표에 대한 몰입정도를 알아보는 대학환경적응(11문 항)으로 4 개의 하위척도로 구성된다. 변수값은 '매우 그렇다 5 점'에서 ‘전혀 그렇지 않다 1점'으로 5점의 Likert 척도로 구성 되어 있는데 점수가 높을수록 대학생활적응 정도가 높음을 의 미한다. 각각의 하위 영역 척도의 내적 일관성 측정 결과, 학업 적응 Chronbach's $\alpha=0.872$, 사회적응 Chronbach's $\alpha=0.761$, 정서적응 Chronbach's $\alpha=0.819$, 대학환경적응 Chronbach's $\alpha=0.844$ 로 나타났으며, 전체 대학생활적응은 Chronbach's $\alpha=0.925$ 로 나타났다.

대학생의 사회적 지지를 측정하기 위해 Park과 Mun [16]이 사용한 척도를 활용하였다. 이 척도는 총 15 문항으로 '친구 지 지', '가족 지지', '교수 지지' 3 개의 하위요인으로 구성되어 있 다. 변수값은 '매우 그렇다 5점'에서 '전혀 그렇지 않다 1점'으 로 5점의 Likert 척도로 구성되어 있는데 점수가 높을수록 사회 적 지지 정도가 높은 것을 의미한다.

각각의 하위 영역 척도의 내적 일관성 측정 결과, 친구 지지 Chronbach's $\alpha=0.934$, 가족 지지 Chronbach's $\alpha=0.945$, 교 수 지지 Chronbach's $\alpha=0.825$ 로 나타났으며, 전체 사회적 지 지는 Chronbach's $\alpha=0.879$ 로 나타났다.

\section{4. 자료 분석 방법}

본 연구의 자료 분석은 SPSS 18.0 통계패키지를 사용하였다. 먼저, 조사 대상자의 인구사회학적 특성 및 주요 변인들의 특성 을 파악하기 위해 빈도분석 및 기술통계를 실시하였다. 다음으 로 인구사회학적 특성 및 주요 변인별 특성에 따른 진로발달 수 준차이를 알아보기 위해 독립표본 t-test를 실시하였다. 마지막 으로 진로발달 수준에 영향을 미치는 요인을 알아보기 위해 분 석 변수들 간의 상관분석과 다중회귀분석을 실시하였으며, 각 분석의 통계적 유의수준은 95\% 신뢰수준(유의도 0.05)으로 검 증하였다.

\section{5. 윤리적 고려}

연구 대상자에게 연구의 목적과 진행절차를 설명한 후 자발
적인 참여하에 참여 동의서에 서명을 받았다. 연구가 진행되는 동안 대상자가 원하지 않으면 연구에 대한 참여의사를 언제든 지 철회할 수 있으며 어떠한 불이익도 없다는 것을 설명하였다. 또한 수집된 자료의 내용은 연구의 목적으로만 사용할 것이며 환자의 개인정보는 비밀로 보장됨을 설명하였다. 이러한 절차 를 통하여 대상자의 윤리적인 측면을 고려하고자 최대한 노력 하였다.

\section{결 과}

\section{1. 인구사회학적 특성}

본 연구에서 사용된 조사대상자의 인구사회학적 특성은 Table 1과 같이 나타났다. 먼저 성별로는 여성이 131명(64.5\%), 남성이 72명(35.5\%)으로 여성 비율이 높게 나타났다. 학년은 1 학년 64명(31.5\%), 2학년 86명(42.4\%), 3학년 53명(26.1\%)로 나타났으며, 연령은 평균 22세로 나타났다.

\section{2. 주요 변수 기술통계}

Table 2 는 조사대상자의 주요 변수에 대한 기술 분석 결과이 다. 종속변수인 진로발달 수준은 평균값이 5점 만점 기준 3.54 $(\mathrm{SD}=0.42)$ 로 나타났으며, 독립변수인 대학생활적응은 3.07 $(\mathrm{SD}=0.41)$, 사회적 지지는 3.59 점 $(\mathrm{SD}=0.54)$ 으로 나타났다. 전 체적으로 보통보다 약간 높은 수준으로 나타났는데 사회적 지 지 정도가 가장 높고, 대학생활적응 정도는 낮게 나타났다. 대학 생활적응 하위영역의 평균값은 학업적응 평균값 3.02 , 사회적 응 3.14, 정서적응 2.92 , 대학환경만족 3.27 로 나타나 대학생활 중 심리적 혹은 신체적 불편감을 나타내는 정서적응이 가장 낮 게 나타났고, 대학에 대한 유대정도와 대학의 질에 대한 대학만 족도, 그리고 학업적 목표에 대한 몰입정도를 알아보는 대학환 경적응이 가장 높게 나타났다.

사회적 지지 하위영역 평균값으로 친구 지지 3.83 , 가족 지지 3.97 , 교수 지지가 2.98점으로 가족 지지가 가장 높게 나타난 반 면, 교수 지지가 가장 낮게 나타났다.

다음으로 주요 변수별 특성에 따라 진로발달 수준 평균값 차

Table 1. General characteristics of participants $(\mathrm{N}=203)$

\begin{tabular}{clcc}
\hline Characteristic & Category & N & $\%$ \\
\hline Gender & Male & 72 & 35.5 \\
\multirow{2}{*}{ Grade } & Female & 131 & 64.5 \\
& 1 Grade & 64 & 31.5 \\
\multirow{2}{*}{ Age } & 2 Grade & 86 & 42.4 \\
& 3 Grade & 53 & 26.1 \\
\hline
\end{tabular}


Table 2. Descriptive statistics of key variables $(\mathrm{N}=203)$

\begin{tabular}{|c|c|c|c|c|c|}
\hline Characteristic & Variable & Mean & SD & Minimum & Maximum \\
\hline \multirow[t]{5}{*}{ Dependent variable } & \multirow{2}{*}{$\begin{array}{l}\text { Career development level } \\
\text { College adjustment }\end{array}$} & 3.54 & 0.42 & 2 & 5 \\
\hline & & 3.07 & 0.41 & 2 & 4 \\
\hline & Academic adjustment & 3.02 & 0.47 & 2 & 4 \\
\hline & Social adjustment & 3.14 & 0.41 & 2 & 5 \\
\hline & Emotional adjustment & 2.92 & 0.53 & 1 & 5 \\
\hline \multirow[t]{5}{*}{ Independent variable } & \multirow{2}{*}{ College environment adjustment } & 3.27 & 0.64 & 1 & 5 \\
\hline & & 3.59 & 0.54 & 2 & 5 \\
\hline & Sub-areas $\quad$ Friend support & 3.83 & 0.68 & 1 & 5 \\
\hline & Family support & 3.97 & 0.81 & 1 & 5 \\
\hline & Professor support & 2.98 & 0.76 & 1 & 5 \\
\hline
\end{tabular}

Table 3. Mean score for career development level $(\mathrm{N}=203)$

\begin{tabular}{|c|c|c|c|c|c|c|}
\hline \multicolumn{2}{|r|}{ Characteristic } & Category & N & Mean & SD & $t / F$ \\
\hline \multirow{2}{*}{\multicolumn{2}{|c|}{ Gender }} & Male & 72 & 3.64 & 0.44 & $2.398^{\star}$ \\
\hline & & Female & 130 & 3.49 & 0.40 & \\
\hline \multirow[t]{3}{*}{ Grade } & & 1 Grade & 64 & 3.53 & 0.43 & 0.508 \\
\hline & & 2 Grade & 85 & 3.59 & 0.43 & \\
\hline & & 3 Grade & 53 & 3.47 & 0.38 & \\
\hline \multirow[t]{10}{*}{ College adjustment } & Total & Below average & 102 & 3.40 & 0.38 & $-4.990^{\star * *}$ \\
\hline & & Above average & 100 & 3.68 & 0.41 & \\
\hline & Academic adjustment & Below average & 101 & 3.40 & 0.38 & $-5.223^{\star \star *}$ \\
\hline & & Above average & 96 & 3.70 & 0.42 & \\
\hline & Social adjustment & Below average & 104 & 3.42 & 0.40 & $-4.295^{\star \star \star}$ \\
\hline & & Above average & 97 & 3.67 & 0.40 & \\
\hline & Emotional adjustment & Below average & 101 & 3.46 & 0.39 & $-3.037^{\star \star}$ \\
\hline & & Above average & 98 & 3.63 & 0.43 & \\
\hline & College environment adjustment & Below average & 89 & 3.42 & 0.44 & $-3.843^{\star \star *}$ \\
\hline & & Above average & 111 & 3.64 & 0.37 & \\
\hline \multirow[t]{8}{*}{ Social support } & Total & Below average & 100 & 3.39 & 0.37 & $-5.344^{\star \star *}$ \\
\hline & & Above average & 102 & 3.69 & 0.42 & \\
\hline & Friend support & Below average & 100 & 3.39 & 0.37 & $-5.467^{\star \star *}$ \\
\hline & & Above average & 102 & 3.69 & 0.42 & \\
\hline & Family support & Below average & 73 & 3.40 & 0.39 & $-3.583^{\star \star \star}$ \\
\hline & & Above average & 129 & 3.62 & 0.42 & \\
\hline & Professor support & Below average & 81 & 3.45 & 0.41 & $-2.512^{*}$ \\
\hline & & Above average & 121 & 3.60 & 0.42 & \\
\hline
\end{tabular}

${ }^{\star} p<0.05,{ }^{* *} p<0.01,{ }^{* \star *} p<0.001$.

이 검증을 실시하였다. 인구사회학적 특성에서 성별에 따라, 학 년별로 진로발달 수준을 비교하였고, 독립변수인 대학생활적 응과 사회적 지지의 수준별 진로발달 수준 차이 검증을 실시하 였으며, 결과는 Table 3 과 같다.

우선, 성별에서 남성(3.64)이 여성(3.49)보다 진로발달 수준 이 통계적으로 유의하게 높게 나타났으며 $(p=0.017)$, 학년별로 는 2학년(3.59)이 1학년(3.53), 3학년(3.47)보다 진로발달 수 준이 높게 나타났으나 통계적으로 유의하게 나타나지 않았다 $(p=0.244)$

독립변수인 대학생활적응과 사회적 지지 정도를 각각 전체 와 하위영역별로 평균값 미만과 평균값 이상 집단으로 구분하
여 진로발달 수준 차이를 검증한 결과 모든 영역에서 평균값 이 상 집단이 평균값 미만 집단보다 진로발달 수준이 통계적으로 유의하게 높게 나타났다.

\section{3. 각 변인별 상관관계 분석}

진로발달 영향요인으로 구분된 독립변수인 대학생활적응과 사회적 지지와 종속변수인 진로발달 수준의 상관관계 분석을 실시한 결과는 Table 4 와 같다. 먼저 각 변수들 간의 상관관계 절대값이 0.431 0.471로 나타나 다중공선성의 문제는 존재 하지 않는 것을 알 수 있다. 그리고 각 독립변인과 진로발달 수준 간의 정적 상관관계가 있는 것으로 나타났다. 


\section{4. 대학생활적응과 사회적 지지가 진로발달 수준에 미치는 영향분석}

보건 - 복지계열대학생들의 대학생활적응과 사회적 지지가 진로발달 수준에 미치는 영향을 검증하기 위해 회귀분석을 실 시하였으며, 결과는 Table 5 와 같다. 우선, 회귀분석 결과에서 진로발달 수준에 영향을 미치는 변수들 간의 다중공선성의 문 제가 없는지 살펴보기 위해 VIF 계수를 확인하였고, VIF계수는 1.285 로 나타나 다중공선성에는 문제가 없는 것으로 판단하였다. 보건 - 복지계열대학생들을 대상으로 진로발달 수준 영향 요 인을 검증한 결과 대학생활적응 $(\beta=0.318, p<0.001)$, 사회적 지지 $(\beta=0.222, p<0.001)$ 모두 진로발달 수준에 유의미한 영 향을 미치는 것으로 나타났다. 즉 대학생활적응과 사회적 지지 가 높을수록 진로발달수준이 높은 것으로 나타났다.

이어서 Table 6 은 대학생활적응 및 사회적 지지 하위 영역 각 각 진로발달 수준에 미치는 영향을 살펴보기 위해 다중회귀분 석 한 결과인데, 대학생활적응 하위 영역에서는 학업 적응 ( $\beta=0.313, p<0.01)$ 이, 사회적 지지 하위 영역에서는 친구지 지 $(\beta=0.190, p<0.001)$ 가 진로발달 수준에 유의미한 영향을 미치는 것으로 나타났다. 즉학업적응 정도가 높을수록, 친구 지 지가 많을수록 진로발달수준이 높은 것으로 나타났다.

이러한 분석결과는 보건·복지계열대학생들의 대학생활적 응과 사회적 지지를 더욱 향상시킴으로써 이들의 진로발달을 도울 수 있는 방안이 될 수 있음을 나타낸다고 할 수 있다.

Table 4. Correlation of dependent variable and independent variable(r)

\begin{tabular}{lccc}
\hline & A & B & C \\
\hline College adjustment & 1 & & \\
Social support & $0.471^{\star *}$ & 1 & \\
Career development level & $0.444^{\star *}$ & $0.431^{\star *}$ & 1 \\
\hline
\end{tabular}

${ }^{\star *} p<0.01$.

A, College adjustment; B, Social support; C, Career development level.

\section{고 찰}

대학생활은 청소년기에서 성인기로 넘어가는 변화의 시기로 독립적인 생활을 시작하며, 문제 상황을 직접적으로 해결해 나 가는 시기이다[17]. 자율적인 선택과 선택에 대한 책임을 지며 전문화된 전공 학문 등 새로운 환경을 경험하는 시기로 대학 입 학과 함께 개인의 내적 적응과 자신을 둘러싼 환경과의 적응을 모두 포함하는 대학생활적응을 해야 하며[18], 적극적이고 자 발적인 태도로 새로운 환경에 적응해야 한다[19].

대학생활의 성공적인 적응은 앞으로 사회생활 적응에 기틀 이 된다는 점에서 대학생들에게 매우 중요한 의미를 갖는다. 따 라서 성장과 성숙의 과정이며 과도기에 있는 대학생에게 있어 대학생활적응은 매우 중요한 요소가 아닐 수 없으며, 이 시기에 자신이 처한 상황의 다양한 개인적인 문제를 스스로 대처 해 나 갈 수 있는 능력을 길러야 한다[18]. 또한 대학생활 적응을 어떻 게 효율적으로 하느냐에 따라 진로발달 수준에 있어서도 많은 영향을 미친다. 이러한 대학생들에게는 진로발달이나 진로결 정이 중요한 과업이며, 이는 대학생활적응에 영향을 주게 될 것 이다[20].

본 연구는 예비 취업자로서 보건 - 복지계열대학생들의 진로 발달 수준을 향상시키기 위한 방안으로 대학생활적응과 사회적 지지의 영향 정도를 살펴보았다.

이에 경상남도 $\mathrm{G}$ 지역과 J지역 대학에서 보건 · 복지계열을 전공하는 대학생을 대상으로 임의표본추출방식을 활용하여 수 집된 설문조사자료를 바탕으로 이들의 진로발달 수준에 대학생

Table 5. The predictors of career development level 1

\begin{tabular}{lcccc}
\hline \multicolumn{1}{c}{ Category } & $\beta$ & $\mathrm{t}$ & \\
\cline { 1 - 3 } Constant & 1.767 & $8.239^{\star \star \star}$ & & $\mathrm{F}=34.976^{\star \star \star}$ \\
College adjustment & 0.318 & $4.476^{\star \star *}$ & Adjusted $\mathrm{R}^{2}=0.253$ \\
Social support & 0.222 & $4.128^{\star \star \star}$ & \\
\hline
\end{tabular}

${ }^{* *} p<0.001$.

Table 6. The predictors of career development level 2

\begin{tabular}{llccc}
\hline & Category & $\beta$ & $\mathrm{t}$ & \\
\hline Constant & & 1.753 & $7.570^{\star \star \star}$ & \\
College adjustment & Academic adjustment & 0.313 & $3.438^{\star *}$ & $\mathrm{~F}=12.256^{\star \star *}$ \\
& Social adjustment & -0.131 & -1.338 & $\mathrm{R}^{2}=0.317$ \\
& Emotional adjustment & 0.074 & 1.177 & Adjusted $\mathrm{R}^{2}=0.291$ \\
Social support & College environment adjustment & 0.040 & 0.650 & \\
& Friend support & 0.190 & $3.875^{\star \star \star}$ & \\
& Family support & 0.061 & 1.717 & \\
& Professor support & -0.019 & -0.466 & \\
\hline
\end{tabular}

${ }^{\star *} p<0.01,{ }^{* \star *} p<0.001$ 
활적응과 사회적 지지의 영향 정도를 파악하고자 시도하였다. 이러한 연구결과는 보건 · 복지계열대학생들이 향후 전문가로 서의 역량과 자질을 습득해 나가는 과정에서 대학생활의 적응 을 더욱 높이고 이들을 위한 다양한 지지 체계의 지원을 높임으 로써 궁극적으로 진로발달을 도울 수 있는 방안 마련에 중요한 자료를 제공하게 될 것이다.

본 연구의 결과를 종합하여 제시해 보면, 첫째, 진로발달 수 준 평균값이 5점 만점 기준 3.54으로 나타났으며, 대학생활적 응 평균값은 3.07 , 사회적 지지는 3.59점으로 나타났는데, 주요 변수 중 사회적 지지 정도가 가장 높고, 대학생활적응 정도는 낮 게 나타났다. 대학생활적응 하위영역 평균값으로 학업적응 3.02 , 사회적응 3.14 , 정서적응 2.92 , 대학환경만족 3.27 로 나 타나 정서적응이 가장 낮게 나타났고, 대학환경적응이 가장 높 게 나타났다. 사회적 지지 하위영역의 평균값으로 친구 지지 3.83 , 가족 지지 3.97 , 교수 지지가 2.98점으로 가족 지지가 가 장 높게 나타난 반면, 교수 지지가 가장 낮게 나타났다.

둘째, 대학생활적응과 사회적 지지 정도를 각각 전체와 하위 영역별로 평균값 미만과 평균값 이상 집단으로 구분하여 진로 발달 수준 차이를 검증한 결과 모든 영역에서 평균값 이상 집단 이 평균값 미만 집단보다 진로발달 수준이 높게 나타났으며, 통 계적으로 유의미한 차이를 나타내었다.

셋째, 보건 - 복지계열대학생들을 대상으로 진로발달 수준 영향 요인을 검증한 결과 대학생활적응 $(\beta=0.318, p<0.001)$, 사회적 지지 $(\beta=0.222, p<0.001)$ 모두 진로발달 수준에 유의 미한 영향을 미치는 것으로 나타났다. 즉 대학생활적응이 높을 수록, 사회적 지지가 높을수록 진로발달수준이 높은 것으로 나 타났다. 대학생활적응 하위 영역, 사회적 지지 하위 영역 각각 진로발달 수준에 미치는 영향을 살펴보기 위해 다중회귀분석 한 결과 대학생활적응 하위 영역에서는 학업 적응 $(\beta=0.313, p$ $<0.01)$ 이, 사회적 지지 하위 영역에서는 친구지지 $(\beta=0.190$, $p<0.001)$ 가 진로발달 수준에 유의미한 영향을 미치는 것으로 나타났다. 즉학업적응 정도가 높을수록, 친구 지지가 많을수록 진로발달수준이 높은 것으로 나타났다.

이러한 연구결과에 대한 함의는 다음과 같다.

첫째, 대학생활적응 하위영역 중에서 정서적응이 가장 낮게 나타났는데, 정서적응은 심리적 혹은 신체적 불편감을 나타내 는 것으로 대학생 개인적인 요인으로 볼 수 있다. 개인적 요인이 라 할지라도 정서적응에 영향을 끼칠 수 있는 대학생활전반에 대한 점검이 필요하며, 정서적응 지원을 위한 다양한 지원을 마 련할 필요성을 제기할 수 있다. 예를 들어 개인적 요인에 대한 지 원으로 대학생의 진로적응성의 수준을 향상시키기 위해서는 자
아존중감을 통한 동기부여와 자기주도 학습능력의 개발이 필요 하다.

둘째, 대학생활적응과 사회적 지지가 진로발달 수준에 유의 미한 영향을 미치는 것으로 나타나 기존 선행연구들과 대부분 일치하는 것을 알 수 있다. 즉, 대학생 시기는 자신에게 가장 적 합한 진로를 선택 및 결정하고 선택한 진로를 성공적으로 이행 해야 하는 중요한 진로발달 과업 단계에 놓여 있다. 이렇게 중요 한 시기에 진로발달 과업을 잘 수행하기 위해서는 무엇보다 대 학생활전반에 대한 적응과 다양한 사회적 지지가 대학생의 진 로정체감 및 진로신념에 긍정적인 영향을 줄수 있다. 또한 대학 생들이 부모와 친구, 전공 교수 등과의 상호작용을 통해 구체적 이고 장기적인 계획을 설정할 수 있으며, 이를 통해 진로의 탐색 및 결정의 내적 동기뿐만 아니라 직접적인 진로의 수행에도 영 향을 줄수 있기[21] 때문에 이러한 사회적 지지 제공자들의 지 원이 매우 중요하다. Song과 Hong [22]의 연구에서도 대학생 의 지각한 사회적 지지가 높을수록 본인 스스로의 능력에 대한 자신감인 진로자기효능감은 올바른 진로준비를 위한 행위적인 노력을 향상시키는 것으로 나타났다.

셋째, 대학생활적응 하위영역 중 학업적응이, 사회적 지지 하 위영역 중 친구 지지가 진로발달수준에 유의한 영향을 끼치는 것으로 나타났는데, 이는 진로발달수준에서 무엇보다 학업에 비중이 크다는 현실을 반영하고 있으며, 사회적 지지 제공자 중 동료 관계의 영향력이 크다는 것을 의미한다.

마지막으로 본 연구는 전체 대학생을 연구대상으로 선정하 지 않아 연구결과의 일반화의 한계가 있으며, 사회적 지지를 주 로 지지 제공자를 중심으로 분석하였으나 향후 사회적 지지의 유형에 따른 추가연구의 필요성을 제기할 수 있다.

\section{요 약}

본 연구에서는 보건 - 복지전공 대학생의 대학생활적응과 사 회적 지지가 진로발달수준에 어떤 영향을 미치는지에 대해 검 증하였다. 연구를 위해서 경상남도 $\mathrm{G}$ 지역과 J지역에 소재한 전 문대학내 보건 - 복지전공 대학생을 대상으로 설문조사가 실시 되었고, 총 203부가 분석에 사용되었다. 연구결과를 살펴보면, 우선 각 변인의 평균값은 5점 만점 기준 진로발달수준 3.54 , 대 생활적응 3.07, 사회적 지지 3.59점으로 나타났다. 둘째, 대학 생활적응 하위영역 평균값으로 학업적응 3.02 , 사회적응 3.14 , 정서적응 2.92 , 대학환경만족 3.27 , 사회적 지지 하위영역 평균 값으로 친구 지지 3.83 , 가족 지지 3.97 , 교수 지지가 2.98점으 로 나타났다. 셋째, 진로발달수준 영향 요인을 살펴보기 위해 다 
중회귀분석 한 결과 대학생활적응 $(\beta=0.318, p<0.001)$, 사회 적 지지 $(\beta=0.222, p<0.001)$ 모두 진로발달수준에 유의미한 영향을 미치는 것으로 나타났다. 즉 대학생활적응이 높을수록, 사회적 지지가 높을수록 진로발달수준이 높은 것으로 나타났 다. 마지막으로 대학생활적응 하위 영역, 사회적 지지 하위 영역 각각 진로발달수준에 미치는 영향을 살펴보기 위해 다중회귀분 석 한 결과 대학생활적응 하위 영역에서는 학업 적응 $(\beta=0.313$, $p<0.01)$ 이, 사회적 지지 하위 영역에서는 친구지지 $(\beta=0.190$, $p<0.001)$ 가 진로발달 수준에 유의미한 영향을 미치는 것으로 나타났다. 즉 학업적응 정도가 높을수록, 친구 지지가 많을수록 진로발달수준이 높은 것으로 나타났다. 이러한 연구결과를 바 탕으로 보건 - 복지 전공대학생들의 진로발달수준을 높이기 위 한 대학생활적응과 사회적 지지 지원의 필요성을 제시할 수 있 으며, 이에 따른 제언을 논의하였다.

\section{Acknowledgements: None}

\section{Funding: None}

Conflict of interest: None

\section{REFERENCES}

1. Park SY, Lee DH. Moderating effects of career preparation behavior in the relationship of career decision level and student adaptation to college. The Journal of Vocational Education Research. 2013;32(1):23-38.

2. Ki BW. The relationship of resilience, career attitude maturity and career preparation behavior of college woman. Journal of Career Education Research. 2010;23(4):93-111.

3. Park SH, Park HJ. Coping as a mediator between career-related stress and career decision-making in college students. The Korean Journal of School Psychology. 2009:6(1):67-81.

4. Lim EM, Jang SS. The immediate and continuous effects of career information exploration program using internet. The Korean Journal of Educational Psychology. 2004;18(4):139154.

5. Lee JH, Lee JS, Lyu JS. An analysis of the structural relationship among family resilience, self -determination and commitment to career choice. The Journal of Korean Home Economics Education. 2011;23(4):19-34.

6. Hwang HJ, Paek JY. Effects of self-identity and social support on the leve of career decisions: the mediating effect of career decision-making self-efficacy. Journal of Secretarial Science. 2015;24(1):99-122.

7. Cho MS, Choi KS. A model testing on ego-identity, social sup- port, career decision-making self efficacy, career maturity, and career preparation behavior in late adolescence. Korea Journal of Counseling. 2007;8(3):1085-1099.

8. Yoon HS, Hwang YM, Kim DB, Jang SH. The effects self-differentiation stress coping methods and mental health on life adjustment in university. The Journal of Korean Educational Forum. 2011;10(2):1-25.

9. Homebeck GN, Leake C. Separation-individuation and psychological adjustment in late adolescence. Journal of Youth and Adolescence. 1999;28(5):63-581.

10. Betz NE. Implications of the null environment hypothesis for women's career development and for counseling psychology. Counseling Psychologist. 1989;1:136-144.

11. Cohen S, Hoberman HM. Positive events and social supports as buffers of life change stress. Journal Applied Social Psychology. 1983;13(2):99-125.

12. Gushue GV, Whitson ML. The relationship of ethnic identity and gender role attitudes to the development of career choice goals among black and Italian girls. Journal of Counseling Psychology. 2006;53(3):379-385.

13. Whiston SC, Keller BK. The influences of the family of origin on career development a review and analysis. The Counseling Psychologist. 2004;32(4):493-568.

14. Shin JG, Hwang GH, Jo MS, Park JH. Basic analysis report of youth panel survey 2014. Eumseong: Korea Employment Information Service; 2015 December.

15. Park BH, Chong YS. Student personal characteristics, parent atachment and adjustment in college. Journal of Korean Home Management Association. 2007;25(3):45-57.

16. Park HS, Mun SY. Mediator effect of school life adaptation affecting relationships between university student' $s$ happiness, self-respect and social support. Korean Journal of Local Government \& Administration Studies. 2014;28(3):197-219.

17. Shim YC, Ra DS. The effects of university student's Life stress on suicidal ideation-mediating by attribution and moderating by adjustment to college Life. Korean Journal of Youth Studies. 2012;19(6):203-226

18. Baker RW, Siryk B. Measuring adjustment to college. Journal of Counseling Psychology. 1984;31(2):179-289.

19. Lautz, J, Hawkins D, P'erez AB. The high school visit. Providing College Psychology. 1984;31:179-189.

20. Hwang MH, Park HY. Career development and school adjustment of college students. Journal of Employment and Skills Development. 2005;8(2):157-176.

21. Han JW. Social support and career identity influence career preparation behaviors-the mediating effect of career decision-making self-efficacy-. Journal of Secretarial Science. 2013; 22(2):117-140.

22. Song HS, Hong HY. The influence of social support, career decision-making autonomy on career preparation behaviors: the mediating effect of career decision-making self-efficacy. Korean Journal of Counseling. 2010;11(3):1325-1350. 